\title{
EchoGéo
}

12 | 2010

La rue en Asie

\section{Géographes Génération 1930,...}

Ouvrage de Claude Bataillon

\section{(2) OpenEdition}

Journals

\section{Édition électronique}

URL : https://journals.openedition.org/echogeo/11907

DOI : 10.4000/echogeo. 11907

ISSN : 1963-1197

Éditeur

Pôle de recherche pour l'organisation et la diffusion de l'information géographique (CNRS UMR 8586)

\section{Référence électronique}

"Géographes Génération 1930,... », EchoGéo [En ligne], 12 | 2010, mis en ligne le 31 mai 2010

consulté le 01 août 2021. URL : http://journals.openedition.org/echogeo/11907 ; DOI : https://doi.org/ 10.4000/echogeo. 11907

Ce document a été généré automatiquement le 1 août 2021.

EchoGéo est mis à disposition selon les termes de la licence Creative Commons Attribution - Pas d'Utilisation Commerciale - Pas de Modification 4.0 International (CC BY-NC-ND) 


\section{Géographes Génération 1930,...}

Ouvrage de Claude Bataillon

1 Cet ouvrage s'inscrit dans la tradition de publications biographiques de chercheurs représentatifs d'une discipline, dont la collection «Geographers Biobibliographical studies ", fondée par Philippe Pinchemel, constitue une référence.

2 Son sous titre: «A propos de Roger Brunet, Paul Claval, Ollivier Dollfus, François Durand-Dastes, Armand Frémont, et Fernand Verger " indique les personnalités présentées.

3 Le contenu de ce livre va au delà de la rédaction de notices biographiques. Claude Bataillon s'implique dans ce panorama, dont il a bien connu tous les protagonistes. Il s'interroge sur le rôle de cette génération dans l'histoire institutionnelle, les bouleversements, les innovations scientifiques et pédagogiques marquant la période.

4 La première partie intitulée "récit » met en perspective les carrières des géographes cités, à travers leur cursus scolaire et universitaire : choix de la géographie, obtention de l'agrégation, préparation de la thèse de doctorat, enseignement de la discipline dans divers postes en province et à Paris. Les répercussions, pour chacun, des deux évènements marquants cette génération : guerre d'Algérie et «tourmente des années 1970 » sont aussi examinées.

5 L'auteur aborde en outre des sujets tels que la documentation, vecteur de production et de diffusion des savoirs.

6 La deuxième partie est consacrée aux notices biographiques proprement dites Elle est rédigée à partir de conversations entre Claude Bataillon et ses interlocuteurs. Complétée par un choix de textes personnels et une auto-bibliographie, ces notices mettent en évidence les thématiques spécifiques à chaque géographe.

7 Par sa composition, cet ouvrage peut être utilisé à la fois pour une lecture cursive mais aussi comme manuel de référence pour l'enseignement et la recherche.

Bernadette Joseph 


\section{BIBLIOGRAPHIE}

Bataillon C., 2009. Géographes Génération 1930, ....- préf. Marie -Claire Robic. Paris, Presses universitaires de Rennes, 226 p., Collection Espaces et territoires. ISBN 978-2-7535-0966-5 